\title{
Assumptions about Ecological Scale and Nature Knowing Best Hiding in Environmental Decisions
}

\author{
$\underline{\text { R. Bruce Hull }}^{1}, \underline{\text { David P. Robertson }}^{1}, \underline{\text { David Richert }}^{2}$ Erin Seekamp $^{1}$, and $\underline{\text { Gregory J. Buhyoff }}^{1}$
}

\begin{abstract}
Assumptions about nature are embedded in people's preferences for environmental policy and management. The people we interviewed justified preservationist policies using four assumptions about nature knowing best: nature is balanced, evolution is progressive, technology is suspect, and the Creation is perfect. They justified interventionist policies using three assumptions about nature: it is dynamic, inefficient, and robust. Unstated assumptions about temporal, spatial, and organizational scales further confuse discussions about nature. These findings confirm and extend findings from previous research. Data for our study were derived from interviews with people actively involved in negotiating the fate of forest ecosystems in southwest Virginia: landowners, forest advisors, scientists, state and federal foresters, loggers, and leaders in non-governmental environmental organizations. We argue that differing assumptions about nature constrain people's vision of what environmental conditions can and should exist, thereby constraining the future that can be negotiated. We recommend promoting ecological literacy and a biocultural approach to ecological science.
\end{abstract}

\section{INTRODUCTION}

Assumptions that "nature knows best"-that it is somehow goaldirected toward diversity or a "correct" ecology—are, and will continue to be, difficult obstacles. These beliefs lie at the core of many people's fundamental conceptions of the world. They are exceedingly difficult to examine openly and rationally....(Borden 1993: 301)

Negotiating desired future conditions for natural areas is a glorious yet frustrating task. It is glorious because people possess keen spiritual, cultural, and economic connections to nature. They feel and speak passionately about their god, their love, and their livelihood; and nature is all these things and more. Negotiations are frustrating because natural conditions are so hard to define and discuss. Nature's infinite complexity and social construction make its definition ambiguous and contingent (Botkin 1990, Cronon 1995, Ingerson 1994, Macnaghten and Urry 1998, Merchant 1980, Sagoff 1988). These frustrations are particularly evident in the negotiation train wrecks caused by the preservation/intervention dichotomy. This dichotomy polarizes and thus paralyzes environmental decision-making (Ingerson 1994 Peterson 1995, 1997, Senecah 1996). Examples of this can be found in the classic debates between preservationist John Muir and interventionist Gifford Pinchot, and in Leopold's famous A-B cleavage (Huth 1957, Leopold 1949, Norton 1991, Oelschlaeger 1991). Preservationists' strategies for environmental problems seek to minimize human-caused change to the finely tuned workings of nature while interventionist strategies seek to improve nature's inefficiencies.

Previous research has clarified some of the differences between preservationist and interventionist rationales. These two lines of argument emphasize different outcomes: for example, the preservationist might seek spiritual connections to the Creator or exhibit aesthetic wonderment of natural marvels, while the interventionist might seek to sustain production of merchantable resources at minimal cost. They differ over whose rights take precedence. For example, the preservationist assumes nature to be living, soulful, and deserving of respect, while the interventionist assumes nature to be mechanical and subservient to human rights. They also differ in the faith placed in technology. Preservationists bemoan human arrogance and worry that technology may cause more harm than good, while interventionists look to human ingenuity 
as Earth's ultimate resource. Less well known are the effects of these assumptions about how nature works. People's conceptual models (intuitive understanding) about how nature works may be as important a source of difference between interventionists' and preservationists' positions as are the better-known differences in assumptions about outcomes, rights, and faith in technology. This paper attempts to examine these assumptions about how nature works and, also, it attempts to examine how they are used to justify preservationist and interventionist positions.

A number of scholars have examined how assumptions made within ecology, the science of nature, shape the content of environmental debate. Worster (1994) demonstrates how changing assumptions changed scientific theories and methods. A familiar example is the Clements-Gleason debate that shaped ecological theory for the first half of the $20^{\text {th }}$ century. Clements assumed ecological communities (e.g., ecosystems) possessed organismic qualities: the whole being greater than the sum of the parts. Gleason assumed the parts of a community were much more independent. He argued that the metaphor of a community's successional march toward a predetermined climax was misplaced and it might be more appropriate to think of nature as changing continuously and aimlessly. Ecological researchers who followed Gleason's deductions found a more dynamic and chaotic nature than those who followed Clement's tenets. More recently, Callicott et al. (1999) show how specific scientific terminology used in conservation science, such as ecological integrity and biodiversity, reflect a "compositionalist" bias and are used in arguments to advocate the protection of nonhuman environmental conditions, whereas terms such as sustainability and ecosystem health reflect a "functionalist" bias and are used in arguments to advocate management of ecosystem functions for human benefit. Assumptions about scale also shape the debate. Angermeier (2000), Norton (1995), Demeritt (1994), and others argue that scale is one of the more fundamental means by which nature, ecology, and environmental quality are organized and understood. Spatially, an environmental change can affect a few square meters, a watershed, or the entire globe. Temporal changes can occur quickly or slowly and can last moments or eons. Organizationally, an environmental change may be examined from the perspective of a cell, an organism, a population, a species, a lake, or some other ecologically significant unit. Which spatial, temporal, or organizational scales are employed will determine how an environmental change is evaluated. These findings suggest that differences in our understanding of nature have significant implications for conservation policy, even within the objectivist realm of science.

A few studies have specifically examined how lay understandings of nature shape environmental management and policy. Dunlap (1999) contrasts the different environmental policies resulting from different understandings of nature found in four anglophone cultures: Australia, Canada, New Zealand, and the US. Looking specifically at US history, Weiner (1996) illustrates how policies that encouraged distribution and exploitation of natural resources dominated when people assumed that nature was stable and resilient, whereas policies of wise use and conservation emerged when assumptions changed to suggest nature was fragile and finite. Dizard (1994) examined the controversy over forest-management policies for the Quabbin Reservoir in central Massachusetts. The reservoir managers believed that overgrazing by a protected deer herd was preventing forest regeneration and thus threatening the soil stability, water quality, and water-retention capabilities of the reservoir. Many people who opposed active management (in the form of a deer hunt) used "balance of nature" arguments. These stakeholders argued that preservation was more desireable than intervention because nature knows best and, if just left alone, the forces of nature would regulate the deer population to a "proper" level.

The study by Kempton et al. (1995) is similar to the effort reported here, in that they interviewed experts and members of the public about environmental understandings and policies. In their case, they studied global warming. They found that people who don't believe in a balanced nature were more comfortable with interventionist solutions, whereas people who believe that nature is balanced and/or frail would rather not intervene to solve environmental problems. People typically offered one or more of three explanations for why they think nature knows best and thus why preservationist rather than interventionist strategies are warranted: (1) nature has homeostatic or self-healing properties; (2) nature is vulnerable to large-scale disturbance and might collapse if greatly disturbed by humans; and (3) nature is too complex and unpredictable for humans to safely modify it without the risk of causing more harm than good.

This paper builds on these prior research efforts, particularly those of Kempton et al. (1995), and on 
other studies described in the extended literature review (Appendix 1). The empirical research reported below examines how different assumptions about nature are embedded in the preferences for policy and management of forest landscapes.

\section{METHODS}

We identified 44 people intimately involved in the science, policy, and management of forests in southwestern Virginia. We purposely sought to represent a broad range of the values, concerns, and understandings of nature held by people within the forestry community in this region. We interviewed private consulting foresters, academic scientists, public agency planners and managers, environmental organization leaders, loggers, and forest owners. Our sample was not intended to be statistically representative of the general population; rather, this research is expected to be generally applicable to similar communities with related natural resource management issues in other locales. We conducted indepth interviews using a semi-structured interview guide with specific questions. These interviews were transcribed into a database of 230,000 words. Through multiple analyses, we identified the discursive themes presented in this manuscript. We asked our selected individuals to define conditions that produced good environmental quality ("How do you define good environmental quality?"). To expose assumptions about how nature works, we asked people to explain the rationale behind their definitions ("How do these conditions produce environmental quality?" and "Why can or why can't humans do better than nature in producing environmental quality?"). Although our method of data collection and analysis was guided by the work of numerous discourse scholars, a valuable reference text is the work of social psychologists Potter and Wetherell (1987). Publications with a similar purpose and methods include Peterson's (1997) work on sustainable development, Takacs' (1996) work on biodiversity, Scarce's (2000) work on salmon, and Kempton et al.'s (1995) work on global warming. Appendix 2 contains the complete interview guide and more details about the analysis.

\section{RESULTS}

People's assumptions about how nature works fell into two opposing camps: (1) Nature knows best how to manage itself and (2) Nature does not know best and needs human management. A third cluster of assumptions pertained to scale. People recognized that nature exists at different spatial, temporal, and organizational scales. It is important to understand at the outset that individuals hold multiple and changing assumptions about nature. We observed the same people using different assumptions at different times during an interview. We discuss and illustrate people's assumptions about nature by using direct quotes from the interviews. Shorter quotes made by multiple speakers are indicated in the manuscript by quotation marks. Longer quotes are set in indented paragraphs and are attributed to a specific speaker. We also provide related insights from the literature (typically in the Appendices).

\section{Why nature knows best}

Twenty-five of the 44 people, at some point during the interview, argued that nature knew best. They reasoned that, all other things being equal, forest management practices should minimize "human intervention," "closely mimic" nature, and "let nature take its course." In other words, "Mother Nature, knows best."

... I think in all instances Nature does a better job than we do ... [laughs] we might convince ourselves, or talk ourselves into, or justify with science that what we are doing is improving on Mother Nature, but no, I hardly think ... that you can improve on it." (Forest advisor 3)

The purpose of the research reported here is to go beyond this simple statement of faith in nature by exploring specific assumptions people made about how nature works. Some of the people we interviewed could not articulate the rationale that justified their nature-knows-best beliefs. They simply defined natural conditions as "normal," or as environmental conditions that "belong" and are "supposed to be." By refusing or being unable to be more specific, they merely made a rhetorical switch of one ambiguous term for another-normal for natural. Most people were able to explain why they think nature knows best. Four types of explanations emerged from analysis of these assumptions about nature: (1) nature has selfregulating processes that produce a delicate balance; (2) evolution is progressive, such that more recently evolved conditions are objectively better than previous conditions; (3) nature is unpredictable, and (4) an allknowing supernatural being created a perfect nature. 
Delicate balance: More than half of the respondents (23 of 44) employed, at some point during their interview, a "balance of nature" argument. They suggested that nature was "balanced" or in "harmony" or that there exists an "equilibrium" in nature due to "forces" that "heal," "improve," or otherwise guide nature towards some balanced or healthy state. Most believed this balance was fragile and easily disrupted by human intervention, and that management should therefore be avoided. Some people offered an organismic metaphor to explain how nature maintains a balance. An ecosystem, it was suggested, functioned like an organism with "self-perpetuating," "selfmaintaining" processes that allow it to "heal itself" (see also the literature reviewed in Appendix 1). Some interviewees explained that nature's balance results from the "interconnections" among environmental factors, species, populations, ecosystems, and ecological processes. That is, the complex interconnections in the "web" of life produce some force that "holds things together." The common, but contentious, assumption that diversity leads to stability provides a case in point.

....generally the more diversity you have in the biologic world, the better able and more resilient the ecosystems are to respond to different stresses and not collapse because of monocultures and things like that. (Forest Service 9)

The belief that nature has balance encompasses both static and dynamic visions of nature. The most restrictive understanding of balance, referred to here as a static balance, occurs at a relatively small spatial scale. A nature that is both static and balanced is assumed to exist for each geographical point in the forest. Each and every acre has a specific ideal, balanced state defined by the forces of evolution, succession, and other environmental conditions and processes that produce balance. If disturbed from that state (within the bounds of natural resilience), then these forces work to recreate the balanced conditions: "although it might be changing, it's going through a process that is repeatable [and] inherent to the system." The length of time it takes to rebound depends upon the degree of disruption, but it was typically defined in human time (several to dozens of human generations), rather than geological time (tens of millions of years).

The least restrictive understanding of balance, referred to here as dynamic equilibrium, has larger spatial and longer temporal scales. Variability may characterize the small scale, "...but on a larger scale, you have to have that stability." Somewhere within the larger spatial extent of the forest, a specific set of conditions (i.e., climax) is expected to occur, but the exact location where this set of conditions occurs depends on unpredictable and indeterminate factors, such as ice, fire, and other natural perturbations, wind direction during pollination, and migration by animals, etc.

Evolution: At least 16 respondents reasoned at some point during the interview that species or other ecologically significant units produced by "evolution" were "best" because they have survived the "test" of time or because "natural selection" had "improved" them. People rationalized letting nature (in this case operationalized as evolution) take its course because they assumed natural selection knew better than humans what was right and good. For example, people suggested that native species were better than exotic or domesticated species because the processes and pressures of natural selection ensured that the native species had adapted to "local conditions." Many of our interviewees made this point by arguing that "exotic" or "alien" species were "bad" or "wrong" for an area because they "change[d] ... the natural processes" or were otherwise "out of control" and thereby "muck up the ecosystem." (See also the literature on "evolving nature" reviewed in Appendix 1.)

Limited Human Technology: Twenty respondents argued that the environment is "incredibly complex," that humans "lack...control over [the] natural influences" causing landscape change, and that the "unpredictability" of disturbance and evolutionary events makes forecasting future conditions difficult or impossible. Expecting and planning for annual sustained yields over an extended planning horizon is thus an exercise in wishful fancy. Some people used this reasoning to recommend preservationist policies. Others recommended caution (i.e., careful testing and regulation of new technology). Several people argued against hubris and paraphrased Aldo Leopold's caution that "intelligent tinkering" requires that we "save all the pieces."

Personally I think that man tends to be enormously arrogant and we ought to be humble enough to understand that we have a very limited grasp on what goes on in natural ecosystems. (Environmental organization leader 1) 
Supernatural created perfect nature: Six people explained that nature knows best because the supernatural force creating it knows best. "God" or "Mother Nature" has set in motion a perfect system and humans must tend and keep that system in the condition in which it was received (see also the literature on "supernatural nature" discussed in Appendix 1). Environmental quality is assumed to be highest when human intervention is minimized or mimics perfected nature, thus the preferred management option is to minimize or mimic nature.

We've tried to force our way upon what Mother Nature, or the Lord, the Creator.... the way the cycles that $\mathrm{He}$ set for this earth and stuff, and we've always tried to enforce our ways upon the different things, and it's never worked, and I don't think it ever will work. (Environmental organization leader 3)

\section{Why nature does not know best}

Almost half (20) of our interview participants indicated at some time during their interview that they believed that nature does not know best. They used this reasoning to justify the necessity of human intervention and control over nature. They discounted preservation as illogical because they assumed untouched nature was random, misanthropic, and inefficient. Detailed analysis of their arguments identified three different assumptions about nature. These were: (1) nature is dynamic, it is constantly changing, and many possible natures can exist and indeed have existed, therefore, selecting one of them as a guide for management would be arbitrary and capricious; (2) nature is robust and resilient, therefore, human manipulation will not necessarily damage it, so we might as well manage nature for desired outcomes; and, (3) nature is inefficient and ruthless, human technology can improve and control it.

Nature is dynamic: Some people explained that nature is neither balanced nor stable but rather it is dynamic and frequently "disturbed" by "human" or "natural" causes such as "fire, storms, volcanoes" as well as "roads," "clearcuts," and "invasive species." These perturbations create conditions of constant flux. People used phrases such as "changing," "disturbance regimes," "dynamic equilibrium," "cyclical," and "growing, changing, maturing, dying, re-growing" to describe forests. These people conclude, in essence, that change is the norm, that there is "no such thing as the balance of nature," and that there exists no ideal condition of nature that can serve as an unbiased goal for management or justification for preservation. Because nature is dynamic, there exists no single condition that is objectively better than any other condition. Nature offers an arbitrary and capricious guide for management.

Rather than let nature wander along some random course, humans should manage nature to produce conditions that meet human needs. (See also the literature on "dynamic nature" noted and discussed in Appendix 1.)

.... anybody who knows a great deal about forests knows that they are constantly changing. That there is no such thing as that kind of permanence. It's a myth. (Environmental organization leader 6)

Nature is robust: Earlier we described how some people justified preservation by using assumptions about the balance of nature. We must also point out that nature's balance was used to justify intervention. At least 12 people reasoned that nature's selfregulating properties make it stable and resilient. They argued that trees "grow back," "clearcuts will come back to be valuable timber," and that we can see all around us the "forest that has recovered, that has come back." These respondents explicitly discounted nature's frailty, arguing instead that nature's robust resilience provides reason to actively manage the forest. "Species have been going extinct ever since the ... life arose on earth ..." and life goes on. "I don't think that the world's gonna end because a couple of little critters in minute niches of the environment have become extinct" (see also the literature reviewed in Appendix 1).

For example, a hurricane....Hurricane Hugo might come through here and blow down a hundred acres of poplar and that's a change and it's going to take some time to grow back, but it would more or less with the same species and same processes. (Forest Service 6)

Nature is inefficient and ruthless: People argued that nature is inefficient and that humans can improve upon it by manipulating, improving, and creating the 
building blocks of life. For example, one respondent stated that "...engineering wise, there are things you can do for the forest that the forest can't do for itself." Human creativity and resourcefulness can improve upon what nature does. Humans can "control" or "manage" the dynamics of nature that otherwise disrupt the regular flow of desired goods and services: "we can just manage the way that it [nature] changes in a more productive, scientific manner." One landowner specifically described how silvicultural thinning practices "help" the forest recover from its "naturally" overcrowded condition.

That new forest, if you let it go promiscuous, it's not going to work. Nature will crowd it [deleted three lines] ... and you've got to recognize that and you [humans] have to do something to help that tree out ... (Landowner 1)

Several people (6) used similar logic to suggest that intervention is required to produce goods and services valued by humans. Life is difficult and human survival requires the management of nature. We live in a competitive world and "Nature on its own is just purely ruthless." Humans, just like other species, need to eke out their existence. Nature does not nurture human existence. Rather, it is harsh and unforgiving and, if we don't manipulate it, it will "manipulate us" (note the literature we review in Appendix 1).

Life exists on this earth not because of nature, but in spite of it, and now for the first time in the 5 billion years this planet has been in existence, there's a species in existence on this Earth that can change that, and for the better, and that's us. Unfortunately, a lot of us change it for the worse....well that's.... what we've got to stop. But this bit about....this [expletive deleted] about....if that's the way it is in Nature, that's the perfect way-nothing could be farther from the truth. (Logger 2)

\section{Assumptions about temporal, spatial, and organizational scale}

Our interview data suggest that people's understanding of nature varies according to temporal, spatial, and organizational scales. Different scales produce very different concerns about environmental management and policy. Time is at the core of many conceptualizations of environmental quality. Sustainability, for example, requires specifying a timeframe over which forest conditions are deemed sustainable (e.g., a "rotation," "my lifespan, or my children's lifespan," "forever"). People often spoke of "change" and "resilience," which have implicit temporal dimensions. The conditions of the forest after logging or other forest disturbance were expected to be different " $10,20,30$ years down the road" compared with what would "happen in hundreds of years' time." Short-term change (i.e., "2 to 5 years") was more acceptable than long-term or "permanent" change. "Natural" changes were typically described as having longer timeframes (e.g., "geological changes," "evolution," "ice age," and "hundreds and hundreds of years") while human-caused changes occurred more rapidly, hence making them less acceptable: "... most plants and animals can't deal with change that is too fast."

Geographic scale also produces different concerns for environmental policy. Changes caused by logging, insects, ice, fragmentation due to roads or houses, or other factors that occur "on a broad enough scale" were of more concern than the same events occurring over a smaller geographic scale. Respondents talked about "cumulative impacts" that show up "a little bit here, a little bit there, 40 acres here, 100 acres there." Individually these changes may be of little concern. But, collectively and cumulatively they are of great concern. The environmental quality of a large forest or ecosystem may be "resilient" to and perhaps even benefit from small-scale disturbances, but will be vulnerable if these disturbances affect a region. Those involved in the US Forest Service Plan revision were particularly sensitive to geographic scale, recognizing that their forest is divided into "stands," and "zones," and "districts" and that even the whole forest fit within the larger "Southern Appalachian Planning Region." Their recommendations for planning varied with this geographic scale.

Finally, many of the respondents' explanations of how nature works exhibited differences in what we term organizational scale. Nature has many ecologically significant units, including "cells," "organisms," "populations," "species," "habitat," “ecosystems," "energy" flows, "nutrient cycles," "diversity," etc. The organizational strategy adopted determines the ecologically significant unit of concern, which, in turn, determines preferences for environmental policies. For example, definitions of environmental quality 
depended upon whether the person was focusing on individual species ("trees" or even more specifically "pines"), collectives of species (e.g., "ecosystems" or "biodiversity"), collectives of collectives (e.g., "forest" or "biosphere"), or individual organisms (i.e., a "tree").

I mean dead trees are a part of forest health and ecosystem health. Insects, diseases, fire, windstorms, ice, glaciers, I mean all of that fits into a healthy forest. Certainly if you look at tree health, I view tree health much differently because a tree is like a human being. It's born, it matures, grows old, and it dies. [Three lines of a similar vein are deleted here]....So tree health is a very specific thing to me. I mean you can look at a tree and you can tell if it is healthy or not, but in a healthy forest there are going to be unhealthy trees. (Forest Service 9)

Demonstrating how the choice of an organizational unit influences the understanding and discussion of nature can be illustrated by examining how interviewees defined "diversity." At least two different strategies surfaced: structural and species diversity. Structural diversity refers to diversity in "age-classes," "habitat types," "communities," "ecosystems," canopy structures (e.g., "understorey, mid-storey, and overstorey"), and "successional stages" (e.g., "early, middle, and late"). Species diversity refers to diversity in "species types," "species abundance," "species richness," species rarity (or "commonness"), as well as "exotic" and "native" qualities of species. The goals of management may be to maintain or enhance diversity. However, dramatically different actions would result from the two different interpretations of diversity. This distinction between structural and species diversity parallels Callicott et al.'s (1999) distinction between functionalists and compositionalists. Scientific literature includes yet other definitions of diversity (Heywood 1995, Takacs 1995).

Obviously, preferences for environmental policies depend upon scale. The degree of concern an environmental change elicits, for example, depends on the spatial and temporal scale of the change. We observed this dependency, in one form or another, in most descriptions and explanations of environmental quality. People differed from one another in the scales they used and the same person often used different scales within the same interview. For example, one respondent began speaking about "silt that washes off of [this] roadway" and how it could be a problem because it "eventually dumps into the Chesapeake Bay." In a matter of a few sentences, the discussion of environmental quality evidenced a dramatic increase in spatial scale-from the road he was walking on, to a watershed that encompasses several states. This is not a problem or a criticism so much as it is an observation of the complexity of people's understandings of nature.

\section{DISCUSSION}

We found that people explained why nature knew best using four assumptions about nature: nature is delicately balanced; evolution is progressive; technology is limited; and a supernatural being created a perfect nature that cannot be improved. We found that people justified that nature does not know best by using three assumptions about nature: it is dynamic, inefficient, and robust. People in our study who assumed that nature knows best argued with conviction that environmental quality is best "without human influence" and that human management only "degrades" or "destroys" environmental quality. Using these assumptions about nature, people argued that environmental policy should seek to minimize human intervention or to mimic nature in the cases where intervention is unavoidable. People in our study who believed that nature does not know best argued the opposite position, also with conviction: only through "good" or "scientific" management can the forest be made "productive," "achieve sustainability," possess "health" and have "diversity" greater than the "nonaction alternative" of removing human control. A companion paper describes the considerable ambiguity and value biases embedded in key terms used to define environmental quality, such as health, sustainability, biodiversity, and the like (Hull et al. 2001, 2002).

These findings confirm, but also extend, findings from previous research. Dizard (1995) found that people use a "balance of nature" rationale to justify their positions against management intervention. Kempton et al. (1995) also found people using a "balance of nature" rationale and, within that rationale, he found assumptions about nature's fragility and unpredictability. We found these same assumptions being used by our sample but several other assumptions were also noted and defined.

It is also important to note that we found no general 
consensus and much contradiction within and between the individuals we studied. That is, most people employed multiple assumptions about how nature works, and some employed contradictory assumptions. Illustrations of contradictions within an individual's definition of environmental quality can be found in (Hull et al. 2002).

Finally, we found that discussions about environmental quality and environmental policy are scale dependent. People must and do make assumptions about temporal, spatial, and organizational scales.

\section{SOME SPECULATIVE IDEAS AND PROPOSALS}

How do we negotiate environmental policy in the context of hidden and embedded assumptions? Being precise about the geographical and temporal scales embedded in different definitions of nature is one solution. It may improve communication and eliminate some misunderstandings. Although this approach may work for scale, assumptions about whether nature knows best typically lie deeper below the surface. As a result, these assumptions are harder to expose or change. They have a polarizing effect that can paralyze negotiations, eliminating opportunities to explore potential common ground (e.g., Ingerson 1994, Peterson 1995, 1997, Senecah 1996).

Science-based education about how nature works is a logical response to this dilemma. It may be possible, through improved public education, to eliminate or expose assumptions that contradict what science currently tells us nature is and is not (e.g., that evolution is not progressive, that diversity need not produce stability, and that ecology is characterized by chaos and dynamism at least as much as by balance and stasis). By questioning potentially polarizing assumptions, public educational efforts may open up some middle ground upon which environmental negotiations can occur. In some cases, such an approach may prove to be an uphill battle. Assumptions about nature's balance and the presumed link between diversity and stability seem deeply embedded in our history, our science, and our language (Ingerson 1994, Glacken 1967, Worster 1994). Sagoff (1985), for example, reviews how the diversity-stability hypothesis justified numerous important conservation legislation victories well after it became suspect in scientific communities. That is why it is intriguing for us to note that nearly half of our interviewees questioned assumptions about a balanced nature. Perhaps change in public sentiment is in the offing or, more likely, the professional training of our interviewees is responsible for their current set of assumptions. In any case, research such as that reviewed and reported here might help target areas where science-based education is missing or needed, and where it may be most effective.

On the other hand, precise terminology and exposed assumptions may not produce the desired outcome of improved negotiations. Peterson (1997) explains how ambiguity and confusion in environmental negotiations confer the benefit of creating room for stakeholders to find common ground as they struggle through negotiations to understand each other's language and agendas. Norton (1991) argues that stakeholders with seemingly opposing agendas frequently share a great deal of common ground in their preferences for land use and policies. Although stakeholders may differ in why they want a particular outcome and in how they think nature works, they may nonetheless agree on desired future conditions. Many preservationists and interventionists are interested, for example, in keeping forest cover on forest lands rather than clearing such lands for housing developments. If negotiations focus on differences in foundational assumptions, then the potential for finding common ground may decrease. Being explicit about these assumptions may only hasten the polarization and further exacerbate already difficult negotiations by causing people to agree to disagree more quickly.

The challenge of future environmental debates will be to negotiate policies consistent with contemporary ecological understandings of a dynamic, chaotic, and humanized nature. We must transcend the polarization and paralysis produced by competing assumptions about whether nature knows best. Bioculturalism is an emerging view of nature that strives to transcend these issues. It encourages stakeholders to recognize human society as an integral component of ecological systems and to find ways for people to interact and live with nature. A biocultural approach to the study of human ecosystems is increasingly evident in mainstream environmental science, in particular, the growing field of urban ecology (e.g., Collins et al. 2000, Pickett et al. 1997). In addition, bioculturalism is increasingly accepted by the international conservation community, which has long recognized the limited effectiveness of conservation strategies that privilege biological diversity over cultural diversity (Droste et al. 1995, Western and Wright 1994). For bioculturalism to be an 
effective conservation strategy, people must first recognize the conceptual limitations imposed by the intervention/preservation dichotomy and accept humans as integral, functional, and adaptive members of the natural landscape. Toward this end, new ideas and directions can be found in the works of contemporary bioculturalists such as Ashworth (1999), Jordan (1994), Turner (1994), and Pollan (1991). These thought-provoking writers are among a growing contingent of biocultural activists who are designing creative approaches to the human-nature relationship based on the belief that humans can be artful agents of landscape change. Backyard Edens, sunflower forests, the biocolonization of neighboring planets, and the cultivation of a new garden are among bioculturalists' visions of healthy human ecosystems that transcend the intervention/preservation dichotomy.

Responses to this article can be read online at: http://www.consecol.org/vol6/iss2/art12/responses/index.html

\section{Acknowledgments:}

This work was supported, in part, by a cooperative research agreement with the USDA Forest Service North Central Experimental Station.

\section{Appendix 1. Extended Literature Review}

Much has been written on how assumptions about nature have influenced environmental science and policy. This Appendix contains an extended literature review to provide interested readers with introductions and access to additional readings. The review begins with a discussion of Kluckhohn and Strodtbeck (1961) and Thompson et al. (1990). Each provide conceptual analyses of public understandings of nature and how such understandings might influence decision making. The review then continues with brief discussions of topics presented in the same order as they appear in the main text: organismic principle, evolutionary nature, supernatural nature, dynamic nature, inefficient nature.

\section{A three-part model of the human-nature relationship}

Kluckhohn and Strodtbeck (1961:13) advance a "three-point range of variation in the man-nature orientation: Subjugation-to-Nature, Harmony-with-Nature, and Mastery-over-Nature." Below, we briefly describe this threepart model using quotes from Kluckhohn and Strodtbeck (1961:13) and insights from Russo (2000:8).

According to the fatalistic Subjugation orientation, there is little that people can do to protect their land and resources (the nature they possess) in the face of natural hazards (e.g., storms) and other whims of nature (or supernature). In contrast, the Mastery orientation (which Kluckhohn claims is the dominant orientation of most Americans) asserts that "Natural forces of all kinds are to be overcome and put to the use of human beings." This orientation necessitates the use of (if not faith in) technology in mastering nature. Lastly, the Harmony orientation poses "no real separation of man, nature, and supernature. One is simply an extension of the other, and a conception of wholeness derives from their unity."

\section{Four conceptual models of nature}

Thompson et al. (1990) identify and describe four conceptual models on which public understandings of nature and preferences for environmental management are based. (1) In the Nature Random model, nature is understood to be random and unpredictable. We don't know how the environment will respond to perturbation or where it might go and how it might change on its own. Humans are unlikely to understand or control natural forces and prediction is difficult if not impossible. Managers, therefore, must develop the capacity to cope with change from erratic events rather than attempt to predict change or control nature. (2) In the Nature Resilient but Vulnerable model, nature is thought to be stable and resilient enough to absorb some disturbances, such as agricultural practices, that increase output of human-valued resources. However, if pushed too far, nature is vulnerable to collapse or cataclysmic change. Therefore, management should seek to identify the limits to which nature can be pushed (e.g., the sustained yield of a population) in order to minimize the chance of cataclysmic change while 
maximizing desired output. (3) In the Static and Stable Nature model, nature provides a stable equilibrium that is difficult for humans to disturb. Nature repairs itself and returns to a stable state no matter how much humans or natural events alter the system. Managers can therefore adopt a laissez-faire attitude and/or strive to maximize production of goods and services valued by humans. (4) The Nature Vulnerable model is almost the exact opposite. Ecosystems are assumed to be fragile and unforgiving; even small changes may trigger system collapse. Under this scenario, managers must treat ecosystems with great care and caution, typically trying to minimize human intervention and mitigate natural disturbances.

\section{Organismic nature}

Worster (1994), in his review of the history of ecological science, shows how the organismic metaphor of nature has a rich tradition, including the $19^{\text {th }}$ century vitalists and $20^{\text {th }}$ century Clementsians who attribute maturing and self-regulating qualities to ecosystems and other ecologically significant units of nature (see also Egerton 1973, Pimm 1991).

\section{Evolutionary nature}

This preference for and emphasis on naturally evolved species is characteristic of the compositionalist school of ecology as outlined in Calicott et al. (1999). Compositionalists give priority to historically evolved species and conditions within ecosystems. The notion of evolutionary progress has a long history in biological literature (Gould 1989, Mayr 1988, Worster 1994). Long before Darwin proposed natural selection as the mechanism for evolution, explanations for observations documenting a history of change in the natural environment reflected a“...belief in an upward or forward progression in the arrangement of natural objects" (Mayr 1988:42). Therefore, even though some exotic species out-compete native species and perform similar ecosystem functions, they are typically deemed inferior and evaluated negatively because they alter environmental conditions from those that evolution intended (e.g., Noss 1990).

\section{Supernatural nature}

Theories and philosophies of ecology and natural history have a long and rich tradition of reflecting faith in a Creator and Creation. They argue that human manipulation of nature should be minimized so as to respect divine qualities present in plants, animals, and other units of nature (i.e., the vitalism, holism, and organicism movements). These philosophical orientations often assume that units of nature possess some "indwelling, mysterious power that physics or chemistry cannot analyze" (Worster 1994:17). Nature knows best because the Creator designed it and, perhaps, continues to play an active role in its maintenance. Science cannot truly understand and management cannot control these vital powers. In part, these views are a "romantic" reactionary response to the cold, dead, machine metaphor of nature proffered by modernism and reductionist science (Oelschlaeger 1991, Merchant 1980).

The Creator's intentions have also been interpreted throughout history as giving humans complete dominion over nature and hence the right to vigorously and wisely manage it (1980). Although few of our respondents explicitly described the involvement of a supernatural force, many may have been doing so implicitly by attributing progress to evolution or intention to self-regulating properties of nature (i.e., goal-oriented, teleology).

\section{Dynamic nature}

The last several decades of ecological research have increasingly emphasized nature's dynamics over its regularities (Egerton 1973, Heywood 1995). Disturbance ecology and hierarchical patch dynamics are examples of these paradigm shifts (Wu and Locks 1995). Change is the norm, and the type and consequences of change are unpredictable. Botkin (1990) and Pimm (1991) are among the many ecologists who are not only documenting a chaotic and unpredictable nature, but also addressing the political and scientific challenges of managing chaos. What should be management's guiding philosophy if nature's trajectory is chaotic? What is a manager to do if air disturbed by a butterfly in Brazil can produce forest-destroying wind and thunderstorms in New York? Adaptive 
management is one response. It assumes change, uncertainty, and unpredictability in nature (Holling 1978). Managers monitor the changing conditions and the consequences of management actions, constantly adapting management strategies based on what is learned. For example, Botkin (1980:155-156) recommends revising the ideal of sustained yield from the stability-driven expectations of equal annual harvests to a dynamic-driven expectation of long-term average yield with variations within shorter time periods.

\section{Inefficient nature}

Justifications to manipulate and manage nature for the good of humanity have a long and distinguished history. White (1967) has argued, although not without controversy, that the Judeo-Christian traditions encourage people to subdue, dominate, and control Earth so as to satisfy human wants and needs while repressing animal instincts and fleshy appetites. Natural philosophers and scholars of the Enlightenment (e.g., Bacon and Linnaeus) argue that humans should vigorously and wisely manage nature so as to improve the Garden, finish the task left by God, and create Paradise on Earth (Passmore 1980, Oelschlaeger 1991, Worster 1994). For many centuries, agriculture has been the science, art, and philosophy of controlling the productivity and improving the efficiency of nature. In the early $20^{\text {th }}$ century, Gifford Pinchot and other progressive conservationists extended the technique and philosophy of agriculture to the more natural forested landscape in the hopes of extracting the greatest economic gain for the greatest number of people for the longest reasonable time (Worster 1994). More recently, ecological theories based in thermodynamics and energy flows have been used to illustrate how inefficiently natural systems capture solar energy. Even the most productive ecosystems (which happen to be agricultural, not natural) capture only $1 \%$ of solar energy, the rest is wasted as heat or reflected into space. Even this $1 \%$ is used inefficiently by nature, much energy is lost to heat and decay as it makes its way up the food chain (Woodwell 1970). These analyses and constructions of ecology support management efforts to improve the inefficiencies of nature.

Such logic justifies active management of nature. It requires that considerable faith be placed in human ingenuity and technology. Numerous arguments exist which state that human creativity, not soil, water, or air, is our ultimate resource (Lewis 1992). Dubos (1980), Turner (1994), and others argue that unrealized potentialities and wonders are awaiting human discovery and creation. Ideas such as naturalness are hindrances to humanity because they direct attention backward, toward the past. Instead, they argue, humans should be looking forward, with a co-evolutionary eye toward a future nature of yet-to-be discovered environmental potentialities.

\section{Robust nature}

The prevalence in ecological literature of the balance of nature argument has been discussed above. Of particular interest here is that the same rationale was used to justify two opposite managerial actions: intervention and preservation. The logic robust nature is similar to Thompson et al.'s (1990) benign model of nature (presented above). Managers can adopt a laissez-faire attitude because the environment will always recover no matter how much it has been disturbed. Kempton et al. (1995), in their survey of various public groups, found that the balance of nature argument correlated with people's preferences for management. They found, however, that those believing in balance were more cautious in their advocacy for management. Our findings are similar.

\section{Appendix 2. Expanded Methods}

This Appendix reviews our methods in more detail. Based on a previous study (Hull et al. 2001) and detailed discussions with natural resource professionals, we developed a semi-structured interview guide designed to reveal assumptions and understandings about nature (see below). Our goal was to identify the range of values and concerns typically present in discussions about forest management, not to represent the forestry community statistically. The group labels are not especially powerful for making inferences about the group members because the groups are not mutually exclusive and because there was often as much variability in opinion within each group as among groups. 
Eleven participants were or had been associated with the US Forest Service; most of them were heavily involved in an ongoing revision of the local National Forest Plan, which we used as a focus for their interviews. Ten people were leaders or very active members of environmental organizations influencing forest management and planning. Eight people specialized in offering advice to forest landowners: three extension foresters, three independent consulting foresters, and two industrial foresters. Four people earned their living harvesting/logging trees. Five people were scientists and professors employed by or retired from two major universities. We interviewed six additional people because they owned forested land. However, during the interviews, we learned that at least half of the 44 respondents owned forested land of some type.

The interviews began with general questions about the person's involvement in natural resource management. The next question asked people how they defined and understood the environmental quality of specific forested settings with which they were familiar. In their responses, participants mentioned a variety of terms, including soil quality, productivity, sustainability, biodiversity, naturalness, and forest/ecological health. However, when questioned further, people struggled to define and describe these qualities. Most of their definitions were ambiguous and the logic used to defend them tautological (this ambiguity and tautology are the focus of another paper under review for publication in a related journal).

We then asked interviewees to explain the reasoning behind their definitions of environmental quality. More specifically, we asked respondents to explain how and why the definitions they offered produced environmental quality. In a related question, we asked whether humans could improve upon nature or improve upon the environmental quality nature produces. The purpose behind these questions was to stimulate people to explain their understanding of how nature works and reveal their knowledge of ecology.

Interviews lasted between 20 and 90 minutes. All but one interview was tape recorded and each of these was transcribed verbatim and imported into NUD*IST (1997), a qualitative data analysis computer software program that we used to organize our analysis. Approximately 238000 words form the database for this study.

Analysis of the interview data sought to identify discursive themes and patterns. The analytical process was iterative. Theme identification evolved through repeated analysis of the original transcripts and of our evolving identification and interpretation of themes. A coding scheme for the interview data evolved and was refined over several months of working with the data. The interviews were coded into NUD*IST using this scheme. That program facilitates organizing and summarizing textual units into a structure such as that presented in the "Results" section of this paper. Intermediate results were presented to forestry professionals and also mailed to half the participants as a type of member check. Responses to these presentations were used to modify our organization and understanding of the discursive themes.

Many direct quotes are presented in the manuscript. The lengthier quotes are attributed to a specific respondent (e.g., Environmentalist 1, Landowner 3, etc). Where a blank occurs in a direct quote (i.e., "...") it is because the respondent paused, repeated a word, or stuttered. Deletions, insertions, or the addition of emphasis to the text are noted with square brackets (e.g., [insertion]).

The interview guide follows. The text in square brackets [ ] are notes to the interviewer. The text in parentheses ( ) are probes and alternative phrasings to encourage discussion.

1. What has been your involvement with forestry [or with planning the National Forest]? (Why are you involved?) (What is your purpose?)

2. What is good environmental quality (EQ) of the forest? What makes forested EQ acceptable or unacceptable? How do you define forested EQ? [Let them speak. Record ecological buzzwords so that you can return to talk specifically about each buzzword using questions $2 \mathrm{~A}-2 \mathrm{~F}$.]

(A) What exactly is _ $\mathrm{x}$ __ ? Or what exactly do you mean by _ $\mathrm{x}$ _ [i.e., $\mathrm{x}$ is the buzzword mentioned] (define it.)

(B) How does _ _ _ _ produce/relate to environmental quality? How do you explain the link between 
_

(C) Why does (_ $\mathrm{x}_{-}$) matter? [value system]

1. [USFS Forest Plan] Why should the JNF try to plan for _ $\mathrm{x} \_$?

2. [Private forest] Why do you care about it?

(D) How do you recognize __ _ _ on the ground (how is it measured)?

(E) Can you suggest one example of __ $\mathrm{x}$ _ ? [If Forest Service plan, ask for one management prescription in the forest plan's rolling alternative where $\mathrm{x}$ is found. If forester or forest advisor, ask for forest they know or have worked or own.] What, specifically, is it about this place [or plan] that illustrates _____? (F) Can there be acceptable environmental quality without _ $\mathrm{x} \_$? How?

[Repeat Question 2 until buzzwords are exhausted. (Are there any other ways that good environmental quality is defined or known?))

3. What is forest health, and how does it differ from EQ?

4. Can you suggest other understandings of EQ that other folks might have? What is right or wrong about these definitions, if anything? Why do you think these people have different definitions that yours?

5. [If Forest Service Plan informant, ask A, otherwise ask B.]

(A) Can you suggest what the FS or others can do to help resolve some of these problems [you identified that result from conflicting/differing definitions]?

(B) What is the relationship between environmental quality and private property rights? Under what conditions does the government have the right to regulate how people use their forests in order to protect EQ?

6. Can people improve environmental quality beyond what nature does for itself? (Explain.)

7. [If Forest Service Plan informant, ask A, otherwise ask B.]

(A) Do you have any other ideas about how information about EQ can be made more effective in a planning process such as the "..." that involves participation by specialists, scientists, advocacy groups, and the general public?

(B) Is there additional/better information you could use to do a better job managing forests? What would you like to know more about? Why? How should it be made available?

\section{LITERATURE CITED}

Angermeier, P. 2000. The natural imperative for conservation biology. Conservation Biology 14:373-381.

Ashworth, W. 1999. The left hand of Eden: meditations on nature and human nature. Oregon State University Press, Corvallis, Oregon, USA.

Borden, R. J. 1993. A social scientist's perspective. Pages 299-305 in M. J. McDonnell and S. T. A. Pickett, editors. Humans as components of ecosystems: the ecology of subtle human effects and populated areas. Springer-Verlag, New York, New York, USA.

Botkin, D. 1990. Discordant harmonies: a new ecology for the twenty-first century. Oxford University Press, New York, New York, USA.

Callicott, J. B., L. B. Crowder, and K. Mumford. 1999. Current normative concepts in conservation. Conservation Biology 13:22-35.

Collins, J. P., A. Kinzig, N. B. Grimm, W. F. Fagan, D.
Hope, J. Wu, and E. Borer. 2000. A new urban ecology: modeling human communities as integral parts of ecosystems poses special problems for the development and testing of ecological theory. American Scientist 88:416-425.

Cronon, W., editor. 1995. Uncommon ground: toward reinventing nature. W. W. Norton and Company, New York, New York, USA.

Demeritt, D. 1994. Ecology, objectivity and critique in writings on nature and human societies. Journal of Historical Geography 20(1):22-37.

Dizard, J. E. 1994. Going wild: hunting, animal rights, and the contested meaning of nature. University of Massachusetts, Amherst, Massachusetts, USA.

Dubos, R. 1980. The wooing of the earth. Charles Scribner's Sons, New York, New York, USA.

Droste, B., H. Plachter, and M. Rossler. 1995. Cultural landscapes of universal value. Gustav Fischer Verlag, New York, New York, USA. 
Dunlap, T. R. 1999. Nature and the English diaspora: environment and history in the United States, Canada, Australia, and New Zealand. Cambridge University Press, Cambridge, UK.

Egerton, F. N. 1973. Changing concepts of the balance of nature. Quarterly Review of Biology 48:322-350.

Glacken, C. J. 1967. Traces on the Rhodian shore: nature and culture in western thought from ancient times to the end of the eighteenth century. University of California Press, Los Angeles, California, USA.

Gould, S. J. 1989. Wonderful life: the Burgess Shale and the nature of history. W.W. Norton and Company, New York, New York, USA.

Heywood, V. 1995. Global biodiversity assessment. Cambridge University Press, Cambridge, UK.

Holling, C. S., Editor. 1978. Adaptive environmental assessment and management. John Wiley, Chichester, New York, USA.

Hull, R. B., D. Robertson, and A. Kendra. 2001. Public understandings of nature: a case study of local knowledge about 'natural' forest conditions. Society and Natural Resources 14:325-340.

Hull, R. B., E. Seekamp, D. Richert, D. Robertson, and G. J. Buhyoff. 2002. Understandings of environmental quality: ambiguities and values held by environmental professionals. Environmental Management: in press.

Huth, H. 1957. Nature and the American.University of Nebraska Press, Lincoln, Nebraska, USA.

Ingerson, A. 1994. Tracking and testing the nature-culture dichotomy. Pages 43-66 in C. Crumley, editor. Historical ecology: cultural knowledge and changing landscapes. School of American Research, Santa Fe, New Mexico, USA.

Jordan, W. R. III. 1994. "Sunflower forest": ecological restoration as the basis for a new environmental paradigm. Pages 17-34 in A. D. Baldwin, Jr., J. De Luce, and C. Pletsch, editors. Beyond preservation: restoring and inventing landscapes. University of Minnesota Press, Minneapolis, Minnesota, USA.

Kempton, W., J. S. Boster, and J. A. Hartley. 1995. Environmental values in American culture. The MIT Press, Cambridge, Massachussetts, USA.

Kluckhohn, F. R., and F. L. Strodtbeck. 1961. Variations in value orientations. Greenwood Press, Westport, Connecticut, USA.

Leopold, A. 1949. (Reprinted 1967.) A Sand County Almanac. Ballantine Books, New York, New York, USA.

Lewis, M. W. 1992. Green delusions: an environmentalist critique of radical environmentalism. Duke University Press, Durham, North Carolina, USA.

Mayr, E. 1988. Towards a new philosophy of biology: observations of an evolutionist. Harvard University Press, Cambridge, Massachussetts, USA.

Macnaghten, P. and Urry, J. 1998. Contested natures. Sage Publications, Thousand Oaks, California, USA.

Merchant, C. 1980. The death of nature: women, ecology and the scientific revolution. HarperCollins, New York, New York, USA.

Norton, B. G. 1991. Toward unity among environmentalists. Oxford University Press, New York, New York, USA.

Norton, B. G. 1995. Ecological integrity and social values: at what scale? Ecosystem Health 1(4):228-241.

Noss, R. F. 1990. Can we maintain biological and ecological integrity? Conservation Biology 4:241-243.

NUD*IST 1997. Non-numerical unstructured data indexing searching and theory-building. Qualitative Solutions and Research Pty. Ltd., La Trobe University, Australia.

Oelschlaeger, M. 1991. The idea of wilderness: from prehistory to the age of ecology. Yale University Press, New Haven, Connecticut, USA.

Passmore, J. 1980. Man's responsibility for nature: ecological problems and western traditions. Duckworth, London, UK.

Peterson, T. R. 1995. Rooted in the soil: how understanding the perspectives of landowners can enhance the management of environmental disputes. The Quarterly Journal of Speech 81(2):139-166.

Peterson, T. R. 1997. Sharing the earth: the rhetoric of sustainable development. University of South Carolina Press, Columbia, South Carolina, USA.

Pickett, S. T. A., W. R. Burch, S. E. Dalton, T. W. Foresman, J. M. Grove, and R. Rowntree. 1997. A conceptual framework for the study of human ecosystems in urban areas. Urban Ecosystems 1:185-199.

Pimm, S. L. 1991. The balance of nature? Ecological issues in the conservation of species and communities. University of Chicago Press, Chicago, Illinois, USA.

Pollan, M. 1991. Second nature: a gardener's education. Dell Publishers, New York, New York, USA.

Potter, J., and M. Wetherell. 1987. Discourse and social psychology: beyond attitudes and behaviour. Sage Publications, London, UK.

Russo, K. W., editor. 2000. Finding the middle ground: 
insights and applications of the value orientations method. Intercultural Press, Yarmouth, Maine, USA.

Sagoff, M. 1985. Fact and value in ecological science. Environmental Ethics 7(2):99-116.

Sagoff, M. 1988. Ethics, ecology, and the environment: integrating science and law. Tennessee Law Review 56:77229.

Scarce, R. 2000. Fishy business: salmon, biology, and the social constructions of nature. Temple University Press, Philadelphia, Pennsylvania, USA.

Senecah, S. 1996. Forever wild or forever in battle: metaphors of empowerment in the continuing controversy over the Adirondacks. Pages 95-118 in S. A. Muir and A. T. L. Veenendall, editors. Earthtalk: communication empowerment for environmental action. Praeger, Westport, Connecticut, USA.

Takacs, D. 1996. The idea of biodiversity: philosophies of paradise. Johns Hopkins University Press, Baltimore, Maryland, USA.

Thompson, M., R. Ellis, and A. Wildavsky. 1990. Cultural theory. Westview Press, Boulder, Colorado, USA.

Turner, F. 1994. The invented landscape. Pages 35-66 in A. D. Baldwin, J. De Luce, and C. Pletsch, editors. Beyond preservation: restoring and inventing landscapes. University of Minnesota Press, Minneapolis, Minnesota, USA.

Western, D., and R. M. Wright. 1994. Natural connections: perspectives in community-based conservation. Island Press, Washington, DC, USA.

Wiener, J. B. 1996. Beyond the balance of nature. Duke Environmental Law and Policy Forum 7:1-24.

White, L. 1967. The historical roots of our ecological crisis. Science 155:1203-1207.

Woodwell, G. M. 1970. The energy cycle of the biosphere. Scientific America 223(September):64-74.

Worster, D. 1994. Nature's economy: a history of ecological ideas. Cambridge University Press, Cambridge, UK.

Wu, J., and O. L. Loucks. 1995. From balance of nature to hierarchical patch dynamics: a paradigm shift in ecology. The Quarterly Review of Biology 70(4):439-466. 